\title{
O ENSINO DE GEOGRAFIA SOB UMA PERSPECTIVA CRÍTICA E REFLEXIVA
}

\author{
George Luiz Carneiro Dantas \\ georgedantas92@gmail.com \\ Eulália Raquel Gusmão de Carvalho Neto \\ eulalia.gusmao@ifrn.edu.br
}

\section{RESUMO}

DOI: doi.org/10.15628/geoconexoes.2019.8730

A educação sistematizada, mais do que nunca, cumpre importante papel de socialização reflexiva e crítica. Assim, o presente artigo tem como objetivo discutir o ensino e a aprendizagem da geografia. Toma como referência uma investigação desenvolvida durante experiências vivenciadas no chão da escola, proporcionada pelo Programa Institucional de Bolsas de Iniciação à Docência - PIBID. Tal investigação adota a observação participante apoiada na pesquisa qualitativa e fundamenta-se na pedagogia crítica. Portanto, a discussão encontra-se assim organizada: no primeiro momento faz uma discussão sobre o ensino da geografia; posteriormente apresenta um relato de uma das experiências e para finalizar busca responder aos seguintes questionamentos: como o fazer docente pode transformase em uma prática onde a reflexão e análise crítica dos assuntos estudados seja uma constante entre professores e alunos? De que maneira o ensino da geografia pode realizar-se como uma prática dialética que promova a interação social? Conclui que a aula de campo como estratégia metodológica e uma excelente aliada dos livros didáticos, pois preenche lacunas e amplia os horizontes diante dos conceitos estudados. Depreende que o planejamento é fundamental para o seu sucesso e que o ensino da geografia quando fundamentado pela pedagogia crítica, possibilita a formação ética, o desenvolvimento intelectual o e pensamento crítico do educando. Torna-se dinâmico e transformador.

PALAVRAS-CHAVE: Pedagogia Crítica. Ensino. Geografia.

\section{ABSTRACT}

The systematized education, more than ever, has an important role of reflective and critical socialization. Thus, the present article aims to discuss the teaching and learning of geography. It takes as reference an investigation developed during experiences lived on "chão da escola", provided by the Programa Institucional de Bolsas de Iniciação à Docência - PIBID. The research adopts participant observation supported by qualitative research and is based on critical pedagogy. Therefore, the discussion is organized in this way: in the first moment it makes a discussion about the teaching of geography; then presents one experience and, finally, seeks to answer the following questions: how can teaching become a practice where reflection and critical analysis of the subjects studied is a constant between teachers and students? What way can geography teaching take place as a dialectical 
practice that promotes social interaction? The article is concluded explanning that the field class as a methodological strategy is an excellent ally of the didatic books, because it fills gaps and broadens the horizons in front of the studied concepts. However, the planning step is fundamental to field class success and the geography teaching when based by critical pedagogy enables ethical formation, intellectual development and critical thinking of the learner. It becomes dynamic and transformative.

KEY WORDS: Critical Pedagogy. Teaching. Geography.

\section{INTRODUÇÃO}

Considerando o contexto no qual estamos inseridos percebemos que a educação sistematizada, mais do que nunca, cumpre importante papel de socialização. Segundo Pérez Gómez (1998, p. 13) "a espécie humana [...] elabora instrumentos, artefatos, costumes, normas, códigos de comunicação e convivência como mecanismo [...] para sobrevivência dos grupos e da espécie." A escola tornou-se, ao longo de sua institucionalização, um dos lugares mais importantes para o desenvolvimento desses mecanismos.

Nesse sentido, o presente artigo propõe uma discussão sobre o ensino da geografia a partir de uma perspectiva reflexiva e toma como referência a pedagogia crítica, pois segundo Veiga (1994) essa pedagogia estimula a interação social por meio da dialética, prática que procura ver o homem como síntese de múltiplas determinações, contribuindo para que o aluno cidadão possa alcançar o principal objetivo da educação, a transformação do ser humano pensante, consciente, crítico e participativo.

Para que isso aconteça são necessários que os processos de ensino e aprendizagem sejam permeados pelo debate entre professor e aluno e que os conteúdos trabalhados sejam elementos condutores de ações conscientes e transformadoras, ou seja, a prática de uma pedagogia que estimule a reflexão contínua.

Diante do exposto e da nossa atuação como bolsista do Programa Institucional de Bolsas de Iniciação à Docência - PIBID levantamos os seguintes questionamentos:

- Como o fazer docente pode transforma-se em uma prática onde a reflexão e análise crítica dos assuntos estudados seja uma constante entre professores e alunos?

- De que maneira o ensino da geografia pode realizar-se como uma prática dialética que promova a interação social?

Para responder tais questões adotamos a investigação qualitativa a partir da pesquisa participante que, segundo Gil (1991), caracteriza-se por ser uma atividade de pesquisa educacional orientada para a ação; e como instrumento de coleta de dados adotamos a observação participante.

Nossa escolha pela observação participante se deu por considerarmos que essa técnica

[...] poderá reconstruir os processos que ocorrem na vida diária da escola. [...] permitirá integrar os vários momentos da escola e interpretar sua realidade cotidiana. Como tais processos se expressam por meio de elementos e situações diferentes 
que perpassam todos os âmbitos, com a metodologia acima indicada desvelarse-á as tramas reais que se efetivam neste contexto e que se estruturam a partir de pequenas histórias: espaços sociais onde se negocia e se reordena a continuidade das experiências e a atividade escolar. As contradições e incongruências aparentes que se nos encontram mais diversos espaços escolares (salas de aula, reuniões, na estrutura física da escola, etc...) adquirem sentido como resultado de mecanismos diferenciava de reprodução e de apropriação entre outros e mostram as diversas formas que a história - social e individual - está presente na vida cotidiana da escola. (MARTINS, 1996, p. 269)

Dessa forma, por estarmos inseridos no contexto escolar como bolsistas buscamos aplicar os sentidos sobre o ensino da geografia com o objetivo de obter informações, analisar e refletir sobre sua realidade.

Para apresentação da discussão acima proposta nosso artigo encontra-se assim organizado: no primeiro momento fazemos uma discussão sobre o ensino da geografia, objeto principal de nosso estudo, na perspectiva da pedagogia crítica; posteriormente apresentamos o relato de uma experiência vivenciada como bolsista do PIBID e concluímos respondendo as questões acima propostas.

\section{O ENSINO DA GEOGRAFIA E A PEDAGOGIA CRÍTICA}

A geografia é uma disciplina que aborda diversos temas sociais, faz parte da área de conhecimento que contempla as Ciências Humanas e que tem como objeto de estudo o homem em suas relações. Segundo Penteado (2010), a geografia compreende tanto as características do espaço natural em que o homem habita como as formas de ocupação e uso desse espaço. Então, a geografia como Ciência Humana é necessária, de acordo com a autora, para o ajustamento, ou, processo de ação, reação e transformação o meio social a que pertence o educando.

Ainda, conforme Penteado (2010), a geografia é responsável na preparação de um cidadão crítico, pois contribui para que ele possa perceber a sociedade em que vive, possa perceber a si mesmo como agente social e possa perceber e entender o sentido dos processos responsáveis por influenciar e orientar a sociedade. Dessa forma, em sala de aula a geografia precisa ser utilizada como estudo da vida do homem em sociedade.

O ensino da geografia também será dinâmico e transformador quando o professor de integrar conhecimentos de diversas áreas, como é uma disciplina de caráter interdisciplinar, ela proporciona um vasto conjunto de elementos significativos da cultura. Logo, permite ao aluno obter "uma visão menos fragmentada da realidade, [para] compreender como o espaço é produzido pela sociedade e nele atuar de modo consciente e crítico." (Campos, 2010, p.9.).

Nessa mesma perspectiva, a pedagogia crítica considera que a atividade humana baseia-se na interação social. Assim, contribui para que ocorra em sala de aula de geografia a reflexão e análise do assunto estudado tanto por parte do professor como do aluno. Essa pedagogia, de acordo com Veiga (1994), estimula a interação social por meio da dialética, prática que procura ver o homem como síntese de múltiplas determinações. 
Outro aspecto importante é que a educação, segundo Brandão (1981), deve ser realizada como um serviço coletivo prestado a cada indivíduo e que o cidadão possa dela desenvolver-se obtendo o que precisa. Chaves (2017), por sua vez, assegura que assim como a democracia é um valor básico e valioso, exercido pelas pessoas, a educação também deve ser encarada como tal, pois é a preparação para o exercício da mesma. Dessa forma, a educação como um processo vital na formação do ser humano precisa integrar todos os indivíduos, reforçando os laços sociais, segundo Saviani (2003).

No entanto, para que a educação possibilite a formação de alunos críticos e participativo é necessário que haja no ensino debate entre professor e aluno, ou seja, a prática de uma pedagogia que estimule a reflexão contínua para que os conteúdos trabalhados sejam compreendidos de forma significativa.

\title{
3. A AULA DE CAMPO: UMA PERSPECTIVA CRÍTICA PARA 0 ENSINO DA GEOGRAFIA
}

O processo de ensino aprendizagem é um processo que envolve a participação tanto do docente quanto dos discentes. Isso possibilita a construção do conhecimento e o desenvolvimento do raciocínio intelectual. Para tanto é necessário à utilização de metodologias de ensino eficazes como o caso da aula de campo.

Segundo Oliveira e Assis (2009, p. 192)

\begin{abstract}
A aula em campo é uma atividade extra sala/extra escola que envolve, concomitantemente, conteúdos escolares, científicos (ou não) e sociais com a mobilidade espacial; realidade social e seu complexo amalgamado material e imaterial de tradições/novidades. É um movimento que tende elucidar sensações de estranheza, identidade, feiura, beleza, sentimento e até rebeldia do que é observado, entrevistado, fotografado e percorrido.
\end{abstract}

Dessa forma, o movimento realizado por professores e alunos durante a aula de campo "deve dançar no ritmo da relação de saberes problematizado na escola (livros didáticos, trabalho de campo, experiências etc.) e agora, movimentado na realidade 'viva' [...]" (OLIVEIRA e ASSIS, 2009, p. 199).

Nessa perspectiva, em novembro de 2016, alunos do Instituto Federal de Educação, Ciência e Tecnologia do Rio Grande do Norte (IFRN), bolsistas do PIBID, em parceria com a Professora e os alunos de Geografia da Escola Estadual Ferreira Itajubá localizada na zona sul de Natal, capital do Rio Grande do Norte realizaram uma aula de campo no município de Ceará Mirim no Estado do Rio Grande do Norte. Para tanto, definimos como objetivos da aula analisar a influência do Brasil Império na cidade e compreender de que modo o Brasil império ainda está presente no cotidiano dos moradores das cidades.

A escolha da cidade de Ceará Mirim como campo de estudo resultou do fato dessa ser uma cidade que se fundamentou, segundo nos relata Hora Neto $(2015$, p.22) 
[...] por uma dinâmica econômica proporcionada pelo comércio, que, por sua vez, era aquecido pelo vigor da atividade canavieira na região, implantada desde o século XIX. A região do médio vale do rio Ceará-Mirim classificou-se como um objeto natural importante para a construção e desenvolvimento da atividade açucareira em meados do século XIX. Essa atividade econômica incentivou a criação de objetos artificiais que desencadearam no surgimento do núcleo urbano de Ceará-Mirim.

Partimos de trem rumo a Ceará Mirim. A escolha desse transporte se deu com o objetivo de proporcionarmos aos discentes a oportunidade de conhecerem a estação e compreenderem como "o advento da ferrovia representou um mecanismo [...] importante para as cidades como meio de integração e comunicação interurbana e territorial” E como, dessa feita, "[...] as estações de trem passaram a ser vistas como as novas portas de entrada do ambiente urbano" (MEDEIROS E FERREIRA). Ademais, tínhamos como objetivo oportunizar aos alunos a observação da capital por outro olhar, um pouco mais periférico visto que a maioria são moradores da zona sul e não conheciam a realidade das comunidades ribeirinhas do rio Potengi.

Com um auxílio de um guia local e com a constante participação da Professora de Geografia da escola, os alunos puderam conhecer a história do centro histórico da cidade e muitos outros aspectos locais influenciados pela época do Brasil império.

Sobre o papel do professor na aula de campo, Oliveira e Correia (2013, p. 163) nos asseveram que "o professor tem papel fundamental na realização da aula de campo, pois além de planejar toda a atividade, ele vai trabalhar como um mediador entre os conhecimentos existentes nos ambientes visitados e o estudante." A condução do professor possibilita ao aluno uma observação própria ao investigador. Os alunos aguçam os sentidos para conhecerem o objeto estudado e construir um arcabouço que lhes permita a descrição, a análise e a crítica. Elementos essenciais ao estudo da geografia.

Ainda no escopo do planejamento, definimos atividades metodológicas que foram realizadas posteriormente na sala de aula para socialização e avaliação dos conceitos apreendidos. As atividades foram: elaboração de croqui do percurso Natal/Ceará-Mirim/Natal, jornal e exposição de fotos.

Passaremos agora a tecer uma breve reflexão sobre essas atividades. A construção do croqui possibilitou aos alunos trabalhar com conceitos da cartografia e compreender a importância da observação sistematizada para a compreensão e para a análise de um dado objeto de estudo. No que se refere ao emprego do jornal como atividade didático-pedagógica, na aula de geografia, os alunos tiveram a oportunidade de desenvolver habilidades e procedimentos aliados aos conceitos estudados. Pois, como afirmam Paula e Torres (2014, p.17) a aplicação do jornal em sala de aula favorece ao uso de

[...] diferentes linguagens como: textos, charges, tiras, gráficos, tabelas, imagens (fotos, desenhos, mapas), que os auxiliam na compreensão das relações econômicas, sociais, culturais, ambientas e políticas, que envolvem a Geografia tanto local (o espaço vivido do aluno) como nas demais escalas geográficas, possibilitando a este educando associar Geografia à realidade. 
Ainda na busca dessa associação, geografia e realidade, a fotografia se apresenta como um caminho propício. Segundo nos afirmam Dantas e Morais (2007)

\footnotetext{
A fotografia estaria no caminho da intuição sensível ou estética do sensível. Acessada através dessa estratégia, o seu inventário, a sua classificação e a sua ordenação ganham outra dimensão. O olhar e o fazer ancorados na estética do sensível denunciam um estilo que preserva, no interior de sua produção, a natureza de pensar e ordenar o mundo a partir da pluralidade, diversidade e integração em contraposição a homogeneidade e a fragmentação. 0 belo está, justamente, na forma como se compacta essa diversidade, permitindo aos agentes envolvidos no processo, compor mosaicos, cuja geometria revela a dialogia possível entre os materiais envolvidos no contexto da produção.
}

O painel fotográfico elaborado pelos alunos possibilitou o resgate do campo de estudo, contexto de produção do conhecimento. Tais atividades tiveram a participação ativa dos estudantes que trabalharam de forma colaborativa com prazer e entusiasmo. Corroborando com o que dizem Figueiredo e Silva (2009), quando afirmam que a aula de campo em Geografia é um instrumento metodológico que envolve, motivam, agrega teoria e prática, além de em sala proporcionar mudanças nos que participam desse processo, pois os mesmos conseguem estabelecer relações com que foi observado.

\section{CONCLUSÕES}

Diante do estudo realizado e da experiência vivenciada como bolsista do PIBID, podemos afirmar que a aula de campo é uma estratégia metodológica que nos permite um fazer docente permeado pela reflexão e pela análise crítica dos assuntos e que o ensino da geografia pode realizar-se como uma prática dialética que promova a interação social quando estão presentes os debates, o diálogo, a reflexão sobre a realidade, sobre a sociedade, sobre os espaços e sobre os lugares estudados.

Compreendemos que tal estratégia metodológica é uma ótima aliada dos livros didáticos, pois preenche lacunas e amplia os horizontes diante dos conceitos estudados. Diante disso, depreendemos que o planejamento é fundamental para o seu sucesso.

Percebemos ainda que o ensino da geografia quando fundamentado pela pedagogia crítica, acarreta o aprimoramento do educando, possibilita a formação ética, o desenvolvimento intelectual e pensamento crítico. Torna-se dinâmico e transformador.

\section{REFERÊNCIAS}

1. BRANDÃO, Carlos Rodrigues. O que é educação. São Paulo: Brasiliense, 2003.

CHAVES, Eduardo. A FILOSOFIA dA EDUCAÇÃO E A ANÁLISE DE CONCEITOS EDUCACIONAIS. Disponível em: < http://www.educadores.diaadia.pr.gov.br/arquivos/File/2010/artigos_teses/filosofia_ da_educacao.pdf $>$. Acesso em: 19 de abril de 2017. 
2. COMPOS, Antonio Carlos. Metodologia do ensino de geografia. São Cristóvão: Universidade Federal de Sergipe, CESAD, 2010. Disponível em: < http://www.cesadufs.com.br/ORBI/public/ uploadCatalago/17554416022012Metodologia_do_Ensino_de_Geografia_Aula_1.pdf>. Acesso em: 19 de abril de 2017.

3. DANTAS, Eugênia Maria; MORAIS Ione Rodrigues Diniz. O ensino de geografia e a imagem: universo de possibilidades Eugênia Maria Dantas. IX Colóquio Internacional de Geocrítica.. Porto Alegre, 28 de maio - 1 de junho de 2007. Universidade Federal do Rio Grande do Sul. Disponível em: http://www.ub.edu/geocrit/9porto/eugenia.htm.

4. FIGUEIREDO Vânia Santos; SILVA, Geane Suelí Castro da. A IMPORTÂNCIA DA AULA DE CAMPO NA PRÁTICA EM GEOGRAFIA. $10^{\circ}$ Encontro nacional de prátiac de ensino de geografia. Disponível em: < http://www.agb.org.br/XENPEG/artigos/GT/GT3/tc3\%20\%2810\%29. pdf>. Acesso em: 24 de abril de 2017.

5. GIL, A. C. Como elaborar projetos de pesquisa. 3. ed. São Paulo: Atlas, 1991.

6. HISSA, C. E. V.; OLIVEIRA, J. R. DE. 0 trabalho de campo: reflexões sobre a tradição geográfica. Boletim Goiano de Geografia, Goiânia, n. 24, p. 31-41, Dezembro, 2004.

7. HORA NETO, José Avelino. Dinâmica da expansão urbana de Ceará-Mirim/RN: aspectos locais e metropolitanos? Dissertação de mestrado. Universidade federal do Rio Grande do Norte. Centro de ciências humanas, letras e arte. Programa de Pós-graduação em estudos urbanos e regionais. Natal, RN, 2015.

8. LIBÂNIO, J. C.Didática. São Paulo: Cortez, 1994.

9. MARTINS, J.B. Observação participante: uma abordagem metodológica para a psicologia escolar. Semina: Ci. Sociais/Humanas, Londrina, v. 17, n. 3, p. 266-273, set. 1996. Disponível em: www. uel.br/revistas/uel/index. php/seminasoc/article/download/9472/8263. Acesso em: 27 de abril de 2017.

10. MEDEIROS, Gabriel L.P.; FERREIRA, Ângela L.A. AS ESTAÇÕES DE TREM DO RIO GRANDE DO NORTE: um estudo sobre a sua implantação no ambiente urbano e inventário de suas condições atuais. Disponível em:<http://hcurb.ct.ufrn.br/_assets/modules/projetosvinculados/projetovinculado_48.pdf>. Acesso em: 28 de abril de 2017.

11. PAULA, Claudia Ponciano de; TORRES, Eloiza Cristiane. O uso de jornal como instrumento pedagógico no ensino de geografia. Os desafios da escola pública paranaense na perspectiva do professor PDE. Artigos. Volume 1. Versão Online. Cadernos PDE Paraná. 2014. Disponível em:http:// www.diaadiaeducacao.pr.gov.br/portals/cadernospde/pdebusca/producoes_pde/2014/2014_uel_ geo_artigo_claudia_ponciano_de_paula.pdf. Acesso em: 29 de abril de 2017.

12. OLIVEIRA, Alana Priscila Lima de; CORREIA, Monica Dorigo. Aula de Campo como Mecanismo Facilitador do Ensino Aprendizagem sobre os Ecossistemas Recifais em Alagoas. ALEXANDRIA Revista de Educação em Ciência e Tecnologia, v.6, n.2, p. 163-190, junho 2013 ISSN 1982-5153.

13. OLIVEIRA, Christian Dennys Monteiro de; ASSIS, Raimundo Jucier Sousa de. Travessias da aula em campo na geografia escolar: a necessidade convertida para além da fábula. Revista Educação e Pesquisa. vol.35 n.1 São Paulo Jan./Apr. 2009. 
14. PENTEADO, Heloísa Dupas. Metodologia do ensino de história e geografia. São Paulo: Cortez, 2010.

15. SACRISTÁN, J. G.; PÉREZ GOMEZ, A. I. Compreender e transformar o ensino. Porto Alegre: Artmed, 1998.

16. SAVIANI, Dermeval. Escola e democracia: teorias da educação, curvatura da vara, onze teses sobre educação política. Campinas - SP: Autores Associados, 2003.

17. VEIGA, I. P. A. A prática pedagógica do professor de didática. 5. Ed. Campinas, SP: Papirus, 2000. 